\title{
Nanomaterials in Newfoundland: Designing a Lab Kit for Grades 9-12 to Bridge the Gap Between Science and Engineering
}

\author{
Amy Hsiao, Ph.D., M.B.A., P.Eng. \\ Associate Professor, Faculty of Engineering and Applied Science \\ Memorial University of Newfoundland \\ amy.hsiao@mun.ca
}

\begin{abstract}
Innovation has its fundamental roots in engineering and entrepreneurship. This paper presents primary research gathered from high school science teachers from selected $K-12$ schools across Newfoundland and Labrador, Canada, addressing specifically the gaps that they have identified as being most challenging in defining what Engineering is in the realm of science curriculum in grades 9-12. This paper will also describe the development of a hands-on learning tool, a "portable materials science lab kit" that considers the input from these community educators and uses nanomaterials, to demonstrate what Engineering is and how Engineering and Innovation are relevantly applied to the important sectors of the province. The "portable lab kits" are designed for high school classrooms, in which small groups of students work through hands-on laboratory modules focusing on a specific material in a specific application. The "portable lab kits" can also be used by teachers as interactive demonstrations of specific scientific concepts in engineering applications.
\end{abstract}

\section{Introduction}

While advanced courses in physics, chemistry, and biology are offered at the high school level, students in grades 9-12 rarely know what "engineering" really is and what technology-based "innovation" really means. applied in engineering design, and how their innovative ideas can impact their communities. This paper centers on the idea that that these two themes can be better introduced before university, such that motivated young students can see the continuum between their education, how science is applied in engineering design, and how their innovative ideas can impact their communities.

Engineering history also shows that materials science has consistently held a place in engineering education, design, and community. Of the twenty greatest achievements of the 20th century named by the National Academy of Engineering shown in Table 1 [1], more than $80 \%$ are enabled by materials through innovation and entrepreneurial activity. It can be argued that research and development in nanomaterials will further advance these technological achievements of the past century.

\section{Table 1. Great Achievements of the $20^{\text {th }}$ Century} [1]

\begin{tabular}{l}
$\begin{array}{l}\text { "How many of the 20th century's greatest } \\
\text { engineering achievements will you use today? How } \\
\text { many are enabled by materials (noted with an } \\
\text { asterisk*)? }\end{array}$ \\
\begin{tabular}{l|l|} 
Electrification* & $\begin{array}{l}\text { Water supply \& } \\
\text { distribution }\end{array}$ \\
Electronics* & Internet \\
Radio \& TV* & $\begin{array}{l}\text { Refrigeration and air- } \\
\text { conditioning* }\end{array}$ \\
Automobile* & $\begin{array}{l}\text { Telephone* } \\
\text { Computers* }\end{array}$ \\
Airplane* & Highways* \\
Spacecraft* & Household appliances* \\
$\begin{array}{l}\text { Agriculture } \\
\text { mechanization* }\end{array}$ & $\begin{array}{l}\text { Imaging* } \\
\text { Laser and fiber optics* }\end{array}$ \\
Nuclear technologies* & materials* \\
Petroleum and & Health technologies* \\
\hline
\end{tabular} \\
\hline
\end{tabular}




\section{Research Approach}

This research rests on theories of hands-on learning, integrated learning, and continuation learning. It hypothesizes that when an idea or concept is revisited in different contexts and environments, i.e. through kinesic, multidisciplinary, or repeated experiences, the learner will have better understanding of the concept and its applications. Materials science is inherently an interdisciplinary field in which knowledge of chemistry, physics, mathematical modeling, and engineering are often combined in use. In fact, practitioners in the materials science world often refer to a paradigm known as the "processing, performance, properties, and microstructure tetrahedron" to steer their technological advancements. Similarly, entrepreneurship requires in-depth technical expertise as well as various management skills. The proposed research activities will not only support hands-on, integrated, and continuation learning, but also analyze and evaluate the effectiveness of this type of approach.

Specifically, primary research was gathered in the form of qualitative data from science high school teachers across the province of NL, using an inductive approach. Questionnaires and follow-up interviews with randomly selected high school science teachers were conducted. A questionnaire was mailed to the principals of all K-12 and high schools in NL, constituting a total of $\sim 100$ schools, accompanied by a cover letter that explained the purpose of the research and provided four ways for submitting responses (i.e. respondents were given a link to complete the survey online and given the option to return the completed survey by post, fax, or scan in their completed surveys to return as an email attachment). The cover letter also asked each principal to identify and provide a copy of the survey to all teachers who taught science curriculum at the grades 9-12 level. Thus, these science teachers were the respondents to the questionnaire.

The questionnaire was designed to harvest valuable information about several different pedagogical issues and engineering education topics, such as the extent to which science teachers were knowledgeable about engineering, what opinions these teachers had about engineering, what teachers thought about the hands-on laboratory kit concept, how "ready" teachers were to lead demonstrations about engineering materials, and if they had any suggestions or ideas for the laboratory kit.

An extensive literature search was also conducted on pre-existing science experiment or laboratory kits produced by other universities and published as peerreviewed research, as well as websites that sell products for science teachers in high school [2].

\section{Results}

The response rate was $40 \%$ out of the total questionnaires distributed, with $90 \%$ of the responses received via the online link. In addition, $90 \%$ of the respondents were from schools outside of St. John's, the capital city of NL; thus the majority of respondents were from rural NL. Sixty-two (62\%) percent of the respondents were male; $38 \%$ were female. Of all respondents, $71 \%$ indicated that they were aware of at least one student who had plans to become an engineer in the future. Figure 1 shows the distribution of replies across the province. The key demographics of the respondents are shown in Table 2.

Figure 1. Distribution of Questionnaire Responses by School Districts

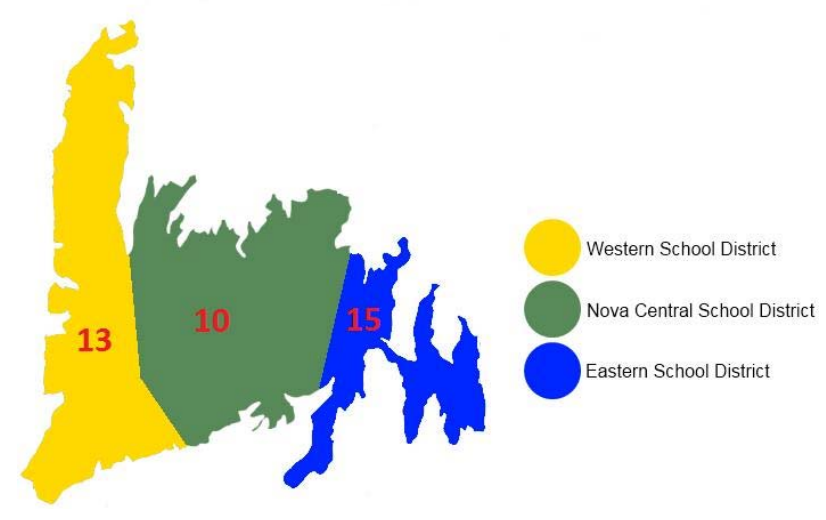

Table 2. Key Demographics of Respondents

\begin{tabular}{|l|c|}
\hline Average Age & 38.3 \\
\hline Average Years Teaching & 13.4 \\
\hline Average Number of Students in Your School & 212.3 \\
\hline
\end{tabular}

The respondents taught a range of science courses from several levels of General Science, Mathematics, Chemistry, Biology, and Physics to Environmental Science, Health, Physical Education, and Earth Systems to Technology and Robotics.

In response to the question asking respondents to describe in general what engineers do, or to define "Engineering", the results were elucidating, with the key words being design, plan, develop, solve, build, apply, practical solutions, and everyday problems. More specifically, the responses included comments such as:

- Change the face of whatever they touch.

- Engineers use physics theory, science, mathematics, and technology to design things for the use of society.

- $\quad$ Plan, develop solutions to everyday problems; this could include building robots, roads, bridges, 
designing electrical mechanisms and industrial needs.

- $\quad$ Engineering is the application of science principles to problems that require technological solutions.

- Aides in the design, development, construction, and maintenance of mechanical, electrical, marine and electronic systems.

- Design and then build objects to meet the needs of people; sometimes they are responsible for overseeing projects (being managers) and other times they are doing the actual work of designing and building; they can work in many types of environments; engineering is a broad field.

- Using knowledge of how the physical world works to develop technologies for the benefit of mankind

- Can't possibly state everything engineers do.

- Engineers develop, integrate, and maintain everything we use in society

- Engineers develop ways to solve problems to certain situations. These people are generally very good at math and science.

- A person who design and/or builds things.

- $\quad$ Engineers use mathematics and scientific knowledge to develop solutions to problems in society and commercial applications.

- Engineers design and build structures (bridges, ships, airplanes, trains, etc), systems (water treatment, computer systems, electrical systems, etc.) and tools and instruments for manufacturing and analysis.

- $\quad$ Engineers are planners and designers mechanical, electrical, nautical etc.

- $\quad$ Solving practical problems; building or repairing structural or mechanical devices. An engineer may manage or maintain the engine of an airplane for example.

- $\quad$ Engineers are professionals who seek to solve a problem in a practical way.

- $\quad$ Engineers manipulate mechanical, electrical or chemical environments for practical purposes.

- $\quad$ Engineers are people who solve various problems with regards to building things (bridges, electrical setup, etc.)

As shown in Table 3, when asked to name a field of engineering, respondents listed first Electrical, Civil, Mechanical, and Chemical Engineering, in that order. It is only upon thinking about other fields of engineering for their second, third, or fourth choices were engineering disciplines such as Aerospace, Biochemical, Nuclear, and Computer Engineering named. Finally, there were some fields listed that are not considered actual engineering disciplines, such as marine, technology, and military engineering.
Table 3. Engineering Disciplines Named by Respondents

\begin{tabular}{|l|l|l|l|}
\hline $\begin{array}{l}\text { Frequency of Discipline Being Named First (number } \\
\text { of respondents) }\end{array}$ \\
\hline $\begin{array}{l}\text { Electrical } \\
(10)\end{array}$ & Civil (10) & $\begin{array}{l}\text { Mechanical } \\
(7)\end{array}$ & $\begin{array}{l}\text { Chemical } \\
(4)\end{array}$ \\
\hline \multicolumn{4}{|l|}{ Frequency of Discipline Being Named Second } \\
\hline $\begin{array}{l}\text { Mechanical } \\
(10)\end{array}$ & $\begin{array}{l}\text { Electrical } \\
(8)\end{array}$ & Civil (5) & Marine (3) \\
\hline Frequency of Discipline Being Named Third \\
\hline Civil (7) & $\begin{array}{l}\text { Electrical } \\
(5)\end{array}$ & $\begin{array}{l}\text { Mechanical } \\
(5)\end{array}$ & $\begin{array}{l}\text { Chemical } \\
(3)\end{array}$ \\
\hline
\end{tabular}

When the teachers were asked to list five characteristics, besides science and mathematical aptitude, that students would be required to possess before the teachers would encourage them to pursue Engineering, they listed initially:

- Curiosity to know

- Work ethic

- Passion

- Dedication

- Problem solver

- Logical/clear thinker

- Hardworking

- Leadership

- Independent work

- Driven

- Disciplined

- Creative

- Common sense

- Innovative

- People-person; ability to communicate

- Articulate

- $\quad$ Ability to manipulate mental models

Second responses included intuition, imagination, being technologically savvy, and having the ability to work in teams. Third responses included flexibility, ability to accept criticism, and strength of character. The majority of respondents did not provide fourth or fifth answers.

The questionnaire also addressed the science teachers' perception of Engineering as a profession, as shown in Table 4. It is clear that the respondents regard engineers as making relevant contributions to society, in terms of economic success, practical applications (i.e. engineers don't deal primarily with theory), and environmental, business, and ethical impact.

An assessment of the science teachers' ability to make the link between what their students are learning 
in the 9-12 science curriculum to what Engineering is, is represented by the questions posed in Table 5 . In this case, it is the respondents' own knowledge and understanding of what Engineering is that will facilitate an effective "bridge" between science and engineering, high school and university, education to innovation. "The bridge" would include the definitions of Engineering and the characteristics of engineers listed by the respondents previously. However, as seen from the results, the teachers do not frequently "make that bridge" nor feel comfortable enough to lead class discussions on what the link is between high school science curriculum and engineering applications. Lastly, these results also indicate that the respondents either do not have access to resources to inform themselves about Engineering or they do not know how or where to access the necessary information.

Table 4. Perception of Respondents on the Societal Impact of Engineers and Engineering (\% response)

\begin{tabular}{|c|c|c|c|c|}
\hline $\begin{array}{l}\text { Strongly } \\
\text { Disagree }\end{array}$ & Disagree & Neutral & Agree & $\begin{array}{c}\text { Strongly } \\
\text { Agree }\end{array}$ \\
\hline \multicolumn{5}{|c|}{ Engineers are highly respected. } \\
\hline 0 & 5.71 & 17.14 & 42.86 & 34.29 \\
\hline \multicolumn{5}{|c|}{ Engineering could be an enjoyable career. } \\
\hline 0 & 0 & 8.57 & 40 & 51.43 \\
\hline \multicolumn{5}{|c|}{$\begin{array}{l}\text { Most of the skills learned in engineering are useful in } \\
\text { everyday life. }\end{array}$} \\
\hline 0 & 0 & 14.29 & 60 & 25.71 \\
\hline \multicolumn{5}{|c|}{ Engineers are important to future economic success. } \\
\hline 0 & 0 & 8.57 & 25.71 & 65.71 \\
\hline \multicolumn{5}{|c|}{ Engineers deal primarily with theory. } \\
\hline 11.43 & 45.71 & 34.29 & 8.57 & 0 \\
\hline \multicolumn{5}{|c|}{ Engineers seldom get involved with business decisions. } \\
\hline 20 & 65.71 & 14.29 & 0 & 0 \\
\hline \multicolumn{5}{|c|}{ Engineers have to deal with environmental issues. } \\
\hline 2.86 & 0 & 2.86 & 45.71 & 48.57 \\
\hline \multicolumn{5}{|c|}{ Engineers need to know about economics. } \\
\hline 2.86 & 0 & 5.71 & 57.14 & 34.29 \\
\hline \multicolumn{5}{|c|}{ Engineers deal with ethical questions about morality. } \\
\hline 2.86 & 17.14 & 22.86 & 42.86 & 14.29 \\
\hline
\end{tabular}

Table 5. Respondents' Perceived Ability to Communicate What Engineering Is (\% response)

\begin{tabular}{|c|c|c|c|c|}
\hline $\begin{array}{l}\text { Strongly } \\
\text { Disagree }\end{array}$ & Disagree & Neutral & Agree & $\begin{array}{l}\text { Strongly } \\
\text { Agree }\end{array}$ \\
\hline \multicolumn{5}{|c|}{$\begin{array}{l}\text { You frequently use the words "Engineer" or } \\
\text { "Engineering” during your classes. }\end{array}$} \\
\hline 8.57 & 48.57 & 25.71 & 11.43 & 5.71 \\
\hline \multicolumn{5}{|c|}{$\begin{array}{l}\text { You are well informed enough to lead discussions about } \\
\text { engineering and help guide aspiring engineers. }\end{array}$} \\
\hline 17.14 & 34.29 & 20 & 22.86 & 5.71 \\
\hline \multicolumn{5}{|c|}{$\begin{array}{l}\text { You know where to find the necessary information to help } \\
\text { those students who want to become engineers. }\end{array}$} \\
\hline 5.71 & 11.43 & 11.43 & 51.43 & 20 \\
\hline \multicolumn{5}{|c|}{$\begin{array}{l}\text { You have the time and resources to improve your } \\
\text { knowledge about engineering. }\end{array}$} \\
\hline 25.71 & 48.57 & 20 & 5.71 & 0 \\
\hline
\end{tabular}

The final components of the questionnaire focused on assessing the usefulness and applicability of a hands-on classroom learning kit, by which both teachers and students would have the information to link science to innovation, design, and ultimately engineering application. Following the results in Table 6, it is clear that a hands-on experience for students and a participative experience for science teachers would improve education of what Engineering is at the preuniversity level and increase interest.

Table 6. Interest in a Hands-on Classroom Learning Kit

\begin{tabular}{|c|c|c|c|c|}
\hline $\begin{array}{l}\text { Strongly } \\
\text { Disagree }\end{array}$ & Disagree & Neutral & Agree & $\begin{array}{l}\text { Strongly } \\
\text { Agree }\end{array}$ \\
\hline \multicolumn{5}{|c|}{$\begin{array}{l}\text { The lab kit described in the cover letter would be an } \\
\text { effective learning tool to inspire and encourage } \\
\text { students to consider engineer as a career choice. }\end{array}$} \\
\hline 0 & 5.71 & 17.14 & 37.14 & 40 \\
\hline \multicolumn{5}{|c|}{$\begin{array}{l}\text { Your students would be interested in seeing } \\
\text { demonstrations involving engineered materials. }\end{array}$} \\
\hline 0 & 2.86 & 14.29 & 34.29 & 48.57 \\
\hline \multicolumn{5}{|c|}{$\begin{array}{l}\text { Students who participate in science fairs could really } \\
\text { benefit from having this kit available as a resource. }\end{array}$} \\
\hline 0 & 0 & 20 & 40 & 40 \\
\hline
\end{tabular}




\section{Analysis and Application}

It is interesting to note that words such as manage, integrate, safety, and professionalism are secondary themes that arose from the questionnaire responses. In addition, the misconception that "marine, technology, and military engineering" are Engineering disciplines reflects the common misuse of the word "engineering". Technologists' education in marine, factory, and defense instrumentation is a common form of vocational training in NL, such that teachers may know of technologists as "engineers" and thus define their knowledge of what Engineering is via interaction with these members of their community. Nonetheless, the primary research gathered focused the development of the hands-on laboratory kit using materials science to demonstrate Engineering applications relevant to the province of Newfoundland and Labrador. As such, the goals of the materials science laboratory kit were clearly defined from the results of the questionnaire, i.e. (1) to emphasize the primary roles of engineers as being to design, plan, develop, solve, build, and apply practical solutions to everyday problems, (2) to focus the experimental modules in the laboratory kit on Electrical, Mechanical, and Civil Engineering examples, as most commonly recognized by the NL community through the respondents, (3) to use the laboratory kit to emphasize five characteristics required of engineers: curiosity, passion, leadership, articulation, and critical thinking, and finally (4) to highlight that engineering makes significant economic, business, ethical, and environmental contributions to society.

The research indicated that the laboratory kit required the development of both a teaching note for instructors and an interactive information manual to guide users of the laboratory kit through each experimental module. Specifically, the information manual was divided into three sections:

Information about the major themes of the lab kit (nanomaterials, materials science and engineering, and innovation); (2) Introductory information about different classes of engineering materials (metals, polymers, ceramics, and composites); and (3) Ideas about how the kit can be integrated with the current high school curriculum along with some recommendations on some other ways this valuable resource can be used to its full potential. The purpose of the manual was to give the user a reference to what will be covered in the lab kit during demonstrations.

The three applications were selected so that common fields of interest familiar to most high school students would be showcased and expanded upon in greater detail. Having captured their attention, the lab kit modules would explore in depth how materials science, engineering and innovation are helping to benefit these fields. Specifically, these fields are:

" 1 . Hockey because it is our national winter sport and our greatest national past-time. Most people in this country are familiar with hockey to some degree, and the hope is that the familiarity and interest in this sport will spark some interest in this section of the lab kit as it explains the science behind hockey.

2. Medicine because there are a lot of materials that are being used in medicine which help improve our health and help us recover from near fatal injuries or illnesses. Also, medicine is a field which is advancing and becoming more sophisticated each year, so it is appropriate to link this lab kit to this field.

3. Environmental Issues because it is one of the most talked about concerns today. Issues like global warming, a sustainable future, helping to save our planet, and ideas for greener lifestyles are constantly in the media. It seems fitting that a resource which deals with how engineering and materials science are helping to fight pollution should be introduced to students.” [3]

Figure 2: Table of Contents for Module on Nanomaterials in Environmental Applications

\begin{tabular}{|cl|}
\hline Biodegradable Packing Materials \\
$\bullet \quad$ Learning Objectives \\
$\bullet \quad$ Background Information \\
$\bullet \quad$ Demonstration \\
$\bullet \quad$ Recap Questions \\
Reusable Shopping Bags \\
$\bullet \quad$ Learning Objectives \\
$\bullet \quad$ Background Information \\
$\bullet \quad$ Demonstration \\
$\bullet \quad$ Recap Questions \\
- References \\
Oil Spill Absorbing Materials \\
$\bullet \quad$ Learning Objectives \\
$\bullet \quad$ Background Information \\
$\bullet \quad$ Demonstration \\
\hline
\end{tabular}

Figure 2 illustrates the Table of Contents for the handbook accompanying the third module in the Nanomaterials in NL lab kit, entitled "Engineering, Materials, and Innovation: Solving Environmental Issues." Additional examples of the modules and interactive information manual will be presented at the technical session of the conference. 


\section{Discussion}

While there is limited knowledge about the development of innovative skills in engineering, there is extensive research literature on the characteristics, information processing habits, and learning styles of engineers. Using Kolb’s cycle of learning, the primary information processing styles of engineers are abstract conceptualization and active experimentation. That is, engineers tend to be what Kolb categorizes as "convergers", who like to consider practical application of ideas, enjoy solving puzzles and answering specific questions, believe in a "single right answer", are action- and design-oriented, and are prone to evaluate situations and thus ready to offer decisions and opinions [4]. While engineers may focus on these two primary learning styles, Kolb suggests that all four components are used for the most enhanced information processing experience; thus, concrete experience and reflective observation should also be included. The objectives of the laboratory kit developed as a result of this research attempted to incorporate all four learning styles such that science teachers and students can experience a concrete classroom activity that is experimental in nature, reflect upon the activity individually and collectively, and develop an understanding of how scientific concepts make the link with engineering applications.

\section{Future Work}

A fully assembled prototype of the lab kit is the next step in this project. A complete list of the required materials and estimated prices has been compiled. Once a prototype kit has been assembled, interactive demonstrations should be conducted. This could involve doing a presentation for a large number of students, for a small class, or for a number of volunteers who wish to learn more about the lab kit. Demonstrations exclusively for teachers and principals may also be done to focus on the user friendly qualities of the kit.

Follow-up input should be collected about the Nanomaterials in Lab Kit while in-use in high schools and other educational organizations. There are two questionnaires that should be created and administered in the next stage of this project. One would be a questionnaire given to students to gather feedback after they have used the lab kit to assess whether this resource accomplishes its objective of defining and demonstrating "what engineering is". This questionnaire should be administered after the students work through the modules, play with the materials, and interact with the information manual. Another survey should be given to teachers or principals only. The survey could be given after an interactive demonstration as well, or in accompaniment with a detailed outline of what the lab kit is and what it includes. Additional surveys would be conducted to assess the avenues for advertising and marketing, specifically asking questions about how many a school would want to buy, how the kits should be distributed, and the funding and pricing nature of the lab kits for educational purposes. Similarly, a website should be designed to make this lab kit as widely available as possible, and the author will work with provincial school boards to facilitate use of the lab kit throughout NL.

\section{Conclusion}

The examples selected for use in the "Nanomaterials in NL" laboratory kit convey a strong message of innovation and engineering application. That is, the materials used were based on basic research and development (R\&D) conducted in industry or in academia and was an invention that was commercialized into a product. The laboratory kit itself is designed to improve the high school environment for developing innovative-thinking students who may be future engineers.

\section{Acknowledgements}

The author wishes to acknowledge the Leslie Harris Centre of Regional Policy and Development at Memorial University from whom she received an Applied Research Fund to support this research. She also acknowledges Jonathon Dunphy, who carried out this project for his first work term.

\section{References}

[1] National Academy of Engineering, "Great Achievements”, www.greatachievements.org/, 2010.

[2] Hsiao, Amy. "Using Everyday Materials to Examine Characteristic Mechanical Properties of Metals, Polymers, and Ceramics”, American Society for Engineering Education Annual Conference \& Exposition Proceedings, 2004.

[3] Dunphy, J. "Report on the Structure, Progress, and Future Recommendations for the Nanomaterials in NL Portable Lab Kit," Memorial University Cooperative Education Winter Work Term Report, April 2010.

[4] Kolb, D. "Management and the Learning Process," California Management Review, XVII (3), 1976, 21-31. 